\title{
Comparative analysis of Laparoscopic versus open surgical radiofrequency ablation for malignant liver tumors
}

\author{
Duhwan Yun ${ }^{1}$, Seokhwan $\mathrm{Kim}^{2}$, Insang Song ${ }^{1}$, and Kwangsik Chun ${ }^{1}$ \\ ${ }^{1}$ Department of Surgery, Chungnam National University Hospital, Daejeon, \\ ${ }^{2}$ Department of Surgery, Asan Medical Center, Seoul, Korea
}

\begin{abstract}
Backgrounds/Aims: This study aims to evaluate the comparative effectiveness of two surgical approaches on the treatment outcomes of radiofrequency ablation (RFA) for malignant liver tumors. Methods: Fifty-seven patients with malignant liver tumors, hepatocellular carcinoma, cholangiocarcinoma and liver metastases, who were candidates for RFA, underwent laparoscopic or open surgical treatments. Results: The patients' characteristics were comparable in the two groups that received open $(n=33,57.9 \%)$ and laparoscopic $(n=24,42.1 \%)$ surgical treatments. There were no statistically significant differences between the two groups in terms of recurrence rate $(p=0.337)$ and overall survival $(p=0.423)$. However, patients in the laparoscopic RFA group had significantly shorter hospital stay (14.1 vs. 5.9 days, $p<0.05$ ) and experienced fewer complications (Grade I: $62.5 \%$ vs. $26.3 \%, p=0.102$ ). Conclusions: Laparoscopic RFA can be performed for malignant liver tumors with lower morbidity rates, less invasiveness and lower expense compared to open surgical approach. (Korean J Hepatobiliary Pancreat Surg 2014;18:122-128)
\end{abstract}

Key Words: Radiofrequency ablation; Malignant liver tumor; Hepatocellular carcinoma; Cholangiocarcinoma; Liver metastasis

\section{INTRODUCTION}

Hepatic resection remains the golden standard for treatment of patients with primary and metastatic liver malignancy. ${ }^{1,2}$ As one of the local ablative techniques available, radiofrequency ablation (RFA) is currently used for treating resectable small hepatocellular carcinoma (HCC). ${ }^{3}$ Although the effectiveness is less well established, RFA has been widely accepted for treating patients with malignant liver tumors unsuitable for hepatectomy.,

Despite its advantages, minimal invasiveness and safety of use, there are some limitations. ${ }^{6}$ RFA could damage adjacent visceral organs when tumors are located peripherally. Especially, percutaneous RFA can cause pneumothorax or damage to the diaphragm when tumors are located near the dome of the liver. Also, multiple liver lesions limit RFA outcomes. $^{7,8}$ To overcome these limitations, intraoperative RFA can be used as an alternative. ${ }^{9,10}$ The use of a laparoscopic or open approach allows placement of RFA electrodes at difficult locations with more accuracy under real time imaging guidance and multiple sites. ${ }^{11}$ In previous studies, intraoperative RFA was shown to be a safe and effective treatment for HCC in difficult locations. ${ }^{12,13}$ However, there is a lack of studies comparing the efficacy of both intraoperative methods. This study aims to evaluate the comparative effectiveness of the two intraoperative approaches on the treatment outcomes of RFA for malignant liver tumors.

\section{MATERIALS AND METHODS}

From December 2008 to July 2013, we performed intraoperative RFA on 57 patients with malignant liver tumors. The Cool-tip ${ }^{\text {TM }}$ (18 Gauge) Radiofrequency Ablation System and the Evident ${ }^{\mathrm{TM}}$ Microwave Ablation System (Covidien, $\mathrm{CO}$, USA). were used for RFA procedures. Intraoperative ultrasound examination and radiofrequency electrode insertion into the center of the tumor were performed by an experienced operator. The median time for the radio-

Received: October 29, 2014; Revised: November 12, 2014; Accepted: November 21, 2014

Corresponding author: Kwangsik Chun

Department of Surgery, Chungnam National University Hospital, 282, Munhwa-ro, Jung-gu, Daejeon 301-721, Korea Tel: +82-42-280-7185, Fax: +82-42-257-8024, E-mail: oxali@cnuh.co.kr

Copyright (C) 2014 by The Korean Association of Hepato-Biliary-Pancreatic Surgery

This is an Open Access article distributed under the terms of the Creative Commons Attribution Non-Commercial License (http://creativecommons.org/ licenses/by-nc/3.0) which permits unrestricted non-commercial use, distribution, and reproduction in any medium, provided the original work is properly cited. Korean Journal of Hepato-Biliary-Pancreatic Surgery • pISSN: $1738-6349 \cdot$ eISSN: $2288-9213$ 
frequency current was 12 minutes (range, 10-28 minutes).

Study patients were 39 men and 18 women, with a median age of 65 years (range, 44-86). The median follow up period was 19 months (range, 3-62). Hepatic resection was not recommended for most of the patients based on tumor multifocality. Indications for intraoperative RFA are determined by patient preferences owing to fear of perioperative morbidity and mortality. Difficult locations for percutaneous approach such as the hepatic dome or caudate lobe are also indicated. The operative approach was applied for tumors adjacent to the diaphragm, or in contact with adjacent structures, or when hepatic resection was deemed obligatory, especially in case of bilobar liver metastases where resection and RFA of contralateral tumors should be performed.

Follow-up contrast enhanced computed tomography was performed immediately after surgery and every three to four monthly in the first 2 years thereafter to evaluate the effectiveness of the treatment. Each time patients visited for follow-up, blood tests were conducted including liver function test and serum alpha-fetoprotein (AFP).

All analyses were performed using the statistical software SPSS ver. 18.0 (SPSS Inc., Chicago, IL, USA). Comparisons between the two groups were done using the Student $\mathrm{t}$-test for continuous data and the $\mathrm{x}^{2}$ test for categorical data. The overall and disease-free survivals were calculated using the Kaplan-Meier method. The relative prognostic significance of the variables in predicting overall and disease-free survival was analyzed using multivariate Cox proportional hazards regression analysis. Significant difference was considered when $p<0.05$.

Table 1. Patients and tumor characteristics

\begin{tabular}{|c|c|c|c|}
\hline Charactertistics & Open & Laparoscopic & $p$-value \\
\hline Patient number & $33(57.9 \%)$ & $24(42.1 \%)$ & 0.738 \\
\hline Gender (male : female) & $22: 11$ & $17: 7$ & 0.738 \\
\hline Age (range) (yrs) & $65.97(44-86)$ & $62.83(48-84)$ & 0.243 \\
\hline Hospital days (range) & $14.13(7-21)$ & $5.89(3-14)$ & 0.00 \\
\hline Follow-up (range) (mos) & $20.85(5-59)$ & $25.83(2-62)$ & 0.288 \\
\hline Size of tumor (mean) $(\mathrm{cm})$ & 1.52 & 1.60 & 0.658 \\
\hline Popup during RFA & 1 & 0 & 1.00 \\
\hline \multicolumn{4}{|l|}{ Location of tumors } \\
\hline Segment 7 & 11 & 2 & 0.026 \\
\hline Subcapsular & 5 & 6 & 0.352 \\
\hline Number of tumors & & & 0.003 \\
\hline 1 & 11 & 18 & \\
\hline 2 & 13 & 5 & \\
\hline 3 & 6 & 1 & \\
\hline 4 & 1 & 0 & \\
\hline 5 & 2 & 0 & \\
\hline Tumor pathology & & & 0.018 \\
\hline Hepatocellular carcinoma & 10 & 16 & \\
\hline Cholangiocarcinoma & 2 & 0 & \\
\hline Metastasis & 21 & 8 & \\
\hline Combined operation (patient no.) & 25 & 5 & 0.00 \\
\hline Liver resection & 19 & 1 & \\
\hline Colectomy & 10 & 1 & \\
\hline Cholecystectomy & 6 & 4 & \\
\hline Gastrectomy & 1 & 0 & \\
\hline Lung surgery & 1 & 0 & \\
\hline Complications (except combined operation) & $5(62.5 \%)$ & $5(26.3 \%)$ & 0.102 \\
\hline Grade I & 5 & 5 & \\
\hline \multicolumn{4}{|l|}{ Recurrence after RFA } \\
\hline Hepatocellular carcinoma $(n=26)$ & 5 & 6 & 0.530 \\
\hline Cholangiocarcinoma $(n=2)$ & 1 & 0 & . \\
\hline Metastasis $(n=29)$ & 12 & 4 & 0.730 \\
\hline
\end{tabular}

RFA, radiofrequency ablation 


\section{RESULTS}

The patient and tumor characteristics are summarized in Tables 1 and 2. There were no significant differences in sex, age, operative method, size of tumor, complication, and whether the tumor location was in the subcapsular region or not. Open surgical RFA was mostly performed at the tumor location of the liver, segment 7 (11 vs. 2, $p=0.026$ ). The majority of patients with HCC were Child-Pugh class A (92.3\%) (Table 2). The cause of HCC was mainly hepatitis B virus infection (61.5\%). Of the 29 patients with metastatic liver tumors, the most common primary malignancy was colorectal cancer $(82.8 \%)$. Most patients with metastatic hepatic malignancy received open surgical RFA ( 21 vs. $8, p=0.018$ ). Of 33 patients who underwent open intraoperative RFA, 25 patients received additional surgery simultaneously; liver resection in 19 , co-

Table 2. Characteristics of tumors according to the tumor pathology

\begin{tabular}{lrcc}
\hline & Open & Laparoscopic & $\begin{array}{c}\text { Patient } \\
(\%)\end{array}$ \\
\hline Hepatocellular carcinoma & 10 & 16 & $26(45.6)$ \\
HBV & 5 & 11 & \\
HCV & 1 & 2 & \\
Alcoholic & 3 & 2 & \\
Idiopathic & 1 & 1 & \\
Child-pugh A & 10 & 14 & \\
Child-pugh B & 1 & 1 & \\
Preoperative TACE & 2 & 3 & \\
Cholangiocarcinoma & 2 & 0 & $2(3.5)$ \\
Metastasis & 21 & 8 & $29(50.9)$ \\
Colorectal & 18 & 6 & \\
Breast & 1 & 1 & \\
Gallbladder & 1 & 0 & \\
Stomach & 1 & 1 &
\end{tabular}

$\mathrm{HBV}$, hepatitis B virus; $\mathrm{HCV}$, hepatitis $\mathrm{C}$ virus; TACE, transarterial chemoembolization lectomy in 10, cholecystectomy in 6 , gastrectomy in 1 , lung resection in 1 . The rate of combined operations was significantly different between the open and laparoscopic RFA groups (25 vs. 5, $p<0.05)$.

The number of tumors was significantly different between the two intraoperative approaches $(p=0.003)$. However, the sum of multiple RFA sites showed no significant differences $(p=0.541)$. Twenty-three and eighteen patients underwent open and laparoscopic RFA for one lesion, respectively. Seven and five patients respectively received each intraoperative approach for two lesions. Another two and one patients were candidates for the respective surgical methods for three lesions. Only one patient underwent open surgical RFA for 4 lesions.

Hospital stay after surgery differed considerably between the two groups $(p<0.05)$. The median number of days in the hospital was fourteen for open surgical RFA (range, 7-37 days) and 5.5 for laparoscopic RFA (range, from 3-14 days).

All of the complications were classified as grade I, pleural effusion, according to the Clavien-Dindo grading system for classification of surgical complications. Although there were no significant differences between the two groups, the laparoscopic RFA group experienced a lower incidence of complications (62.5\% vs. $26.3 \%$, $p=0.102$ ).

One patient with HCC (3.8\%) showed incomplete ablation on the immediate follow-up computed tomography (CT) scan. None of the patients with HCC showed local tumor progression, but ten had a new lesion (4 for open and 4 for laparoscopic approaches). One of the patients with cholangiocarcinoma had local tumor progression after open surgical RFA but no new lesions. In metastasis cases, two (6.9\%) and one (3.4\%) patients who underwent open and laparoscopic RFA respectively had local tumor

Table 3. Patient and tumor characteristics of recurrence cases

\begin{tabular}{cccccccc}
\hline Sex/Age & Histology & $\begin{array}{c}\text { Size } \\
(\mathrm{cm})\end{array}$ & $\begin{array}{c}\text { Location } \\
\text { (segment) }\end{array}$ & $\begin{array}{c}\text { Operation } \\
\text { method }\end{array}$ & $\begin{array}{c}\text { Subcapaular } \\
\text { location }\end{array}$ & $\begin{array}{c}\text { Type of } \\
\text { recurrence }\end{array}$ \\
\hline 1 & $\mathrm{M} / 50$ & $\mathrm{HCC}$ & 1 & $\mathrm{~S} 6$ & Open & + & Incomplete \\
2 & $\mathrm{M} / 64$ & $\mathrm{CCC}$ & 2 & $\mathrm{~S} 4 / 8$ & Open & - & \\
3 & $\mathrm{~F} / 60$ & Meta $(\leftarrow \mathrm{GBC})$ & 1 & $\mathrm{~S} 4 / 8$ & Open & - & Local \\
4 & $\mathrm{~F} / 79$ & Meta $\leftarrow \mathrm{CRC})$ & 1.5 & $\mathrm{~S} 8$ & Open & + & - \\
5 & $\mathrm{M} / 55$ & Meta $(\leftarrow \mathrm{CRC})$ & 1.5 & $\mathrm{~S} 4 / 8$ & Lap & - & \\
\hline
\end{tabular}

HCC, hepatocellular carcinoma; CCC, cholangiocarcinoma; Meta, metastasis; GBC gallbladder cancer; CRC, colorectal cancer 
Table 4. Comparison of recurrence rate after open and laparoscopic ablation

\begin{tabular}{|c|c|c|c|c|c|c|}
\hline & \multicolumn{3}{|c|}{ Open } & \multicolumn{3}{|c|}{ Laparoscopic } \\
\hline & Incomplete & Local & New & Incomplete & Local & New \\
\hline Hepatocellular carcinoma (\%) & $1(1.8)$ & 0 & $4(7.0)$ & 0 & 0 & $6(10.5)$ \\
\hline Cholangiocarca (\%) & 0 & $1(1.8)$ & 0 & 0 & 0 & 0 \\
\hline Metastasis (\%) & 0 & $2(3.5)$ & $10(17.5)$ & 0 & $1(1.8)$ & $3(5.3)$ \\
\hline
\end{tabular}

A

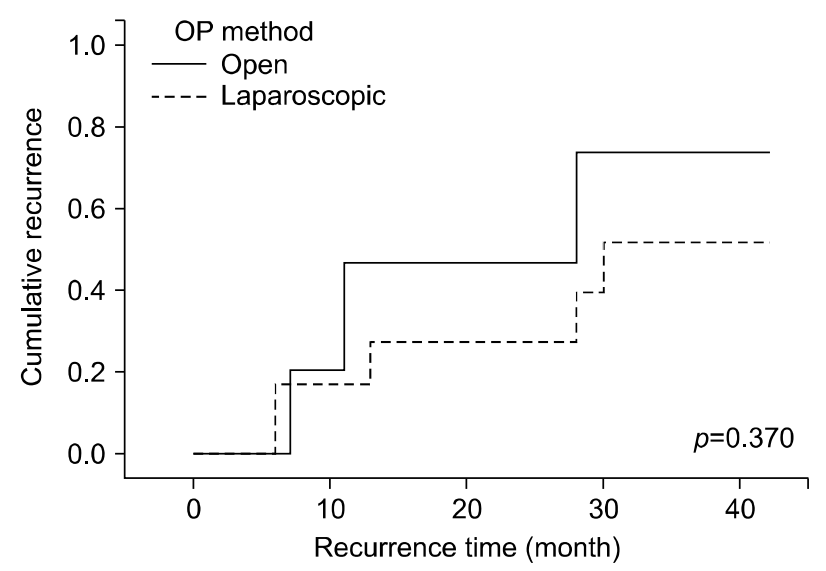

B

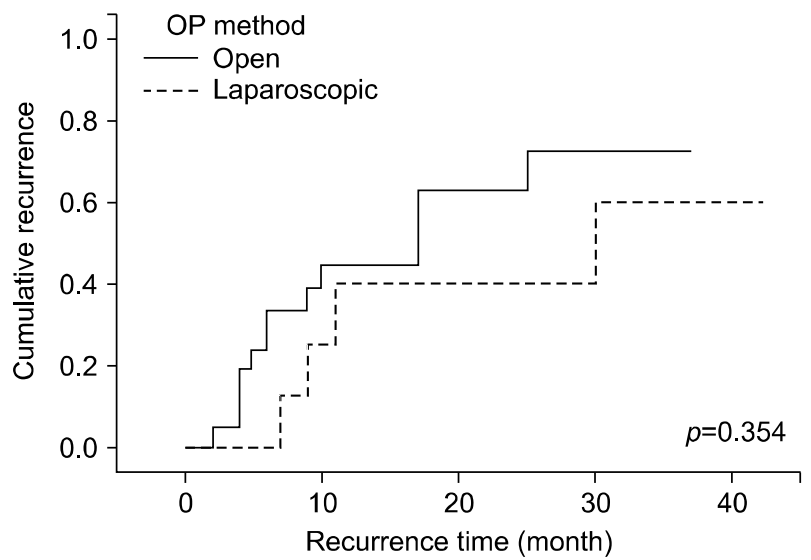

Fig. 1. Comparison of recurrence rates after open and laparoscopic radiofrequency ablation for hepatocellular carcinoma (A) and liver metastasis from colorectal cancer (B).

progression whereas ten $(34.5 \%)$ and three $(33.3 \%)$ had a new lesion (Tables 3, 4). The median disease-free survival time was 11 months for patients with HCC (range, 2-57 months) and 10 months for those with liver metastasis, especially from colorectal cancer (range, 2-54 months). The difference in local recurrence rates after intraoperative RFA was not statistically significant between the two groups according to the tumor pathology. The overall recurrence rate three-years after open and laparoscopic RFA was $73.3 \%$ and $61.4 \%$ for patients with HCC $(p=0.370)$, respectively; the rate was $72.2 \%$ and $60 \%$ for patients with liver metastasis from colorectal cancer, respectively ( $p=0.354)$ (Fig. 1).

During the follow-up period, there were no mortalities associated with the surgery. One patient each with HCC died of disease progression at thirty and at six months after undergoing open and laparoscopic RFA. The three-year overall survival rates of patients with metastatic tumors from colorectal cancer who underwent open and laparoscopic RFA were $83.7 \%$ and $64.0 \%$, respectively (Fig. 2).

Multivariate analysis was performed to evaluate the ef-

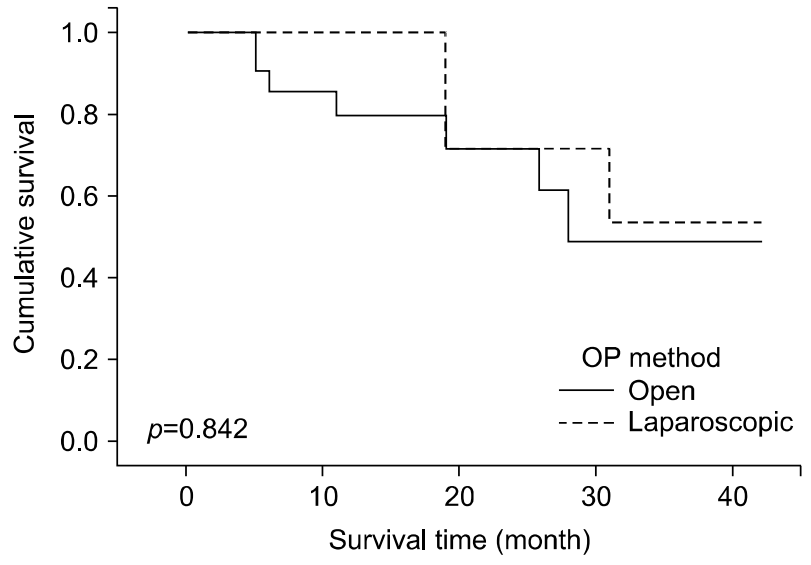

Fig. 2. Comparison of overall survival rates after open and laparoscopic radiofrequency ablation liver metastasis from colorectal cancer.

fect of factors (e.g., number of tumors, tumor pathology, RFA method, subcapsular location, recurrence case, simultaneously combined operation, Child-Pugh classification, whether complications exist, preoperative chemotherapy and TACE) that may potentially influence the tumor recurrence rate and overall survival (Table 5). The number of tumors was the only significant factor affecting 
Table 5. Multivariate analysis of recurrence and overall survival

\begin{tabular}{llc}
\hline & \multicolumn{1}{c}{ Factors } & $p$-value \\
\hline Recurrence & Number of tumors & 0.002 \\
Overall survival & Recurrence & 0.016 \\
& Prior recurrence & 0.001 \\
& Number of tumors & 0.024 \\
\hline
\end{tabular}

the recurrence rate after intraoperative RFA. Recurrence after RFA, recurred case and number of tumors were independent factors affecting overall survival.

\section{DISCUSSION}

Radiologists initially used percutaneous RFA as treatment for solid tumors. Surgeons started to use RFA as a surgical approach for patients with tumors at locations that are too difficult for percutaneous treatment. ${ }^{14}$

Unlike percutaneous treatment, the surgical approach can ablate tumors which are located near major blood vessels or bile ducts and adjacent organs and structures.

Otherwise, for small HCC in locations too difficult to apply a percutaneous approach, intraoperative RFA can be an alternative option for deep-seated tumors. ${ }^{15-17}$

Several studies show that intraoperative RFA (by laparoscopy or laparotomy) results in superior local control compared to percutaneous RFA with similar overall survival and complication rates. ${ }^{18-20}$ To assess the success of RFA treatment, we must closely evaluate the outcome with incomplete treatment, local recurrence, survival rates and complication rates taken into account. ${ }^{21}$ However, there is no consensus among experts on which surgical approach is more practical.

The rate of incomplete ablation was generally reported to be less than $10 \%$ on tumor-by-tumor analysis. ${ }^{22-25}$ In our study, there was only one case $(1.8 \%)$ of incomplete ablation. The patient had HCC in the form of a 1-cm-sized subcapsular lesion located in segment 6 of the liver. Under similar difficult approach conditions in the right posterior segment of the liver (open in 6 and laparoscopic in 7 patients), there was no incomplete treatment in the laparoscopic RFA group.

In a meta-analysis study of local recurrence after hepatic RFA, the total recurrence rate was $14.9 \%$ (352 of 2369) for patients with HCC and 14.7\% (112 of 763) for patients with colon cancer metastases. ${ }^{19}$ In that analysis, significantly fewer local recurrences were observed for a surgical (versus percutaneous) approach, $(p<0.001)$ even for small tumors $(\leq 3 \mathrm{~cm})$. In our study, local recurrence rate was $7.0 \%$ for all-tumor pathologies. Of the four patients with local recurrence, three received open surgical RFA. Two of the three had liver metastasis and the other had cholangiocarcinoma. There was no local recurrence in patients with HCC in the two groups.

In a study of RFA for 235 patients with colorectal liver metastases, the overall survival rates at 3 years were $20.2 \%$. ${ }^{26}$ Also, the mean survival for patients with tumors $<3$ and $>3 \mathrm{~cm}$ was 28 and 20 months, respectively. It was reported that the overall 3 -year survival rates after laparoscopic RFA for 66 patients with HCC were $38 \%{ }^{27}$ In our study, 3-year survival rates for colorectal liver metastases were $49.4 \%$ and $53.6 \%$ according to open and laparoscopic operative approaches, respectively $(p=0.842)$. During the follow-up period, the number of deceased HCC patients was two, and each patient died from disease progression at 30 and 6 months after open and laparoscopic ablation. There was no operative mortality in both groups.

A total of $24(72.7 \%)$ and $6(25 \%)$ patients had complications following open and laparoscopic RFA, respectively $(p<0.05)$. The complications were pleural effusion $(86.7 \%)$, abdominal wall hematoma (3.3\%), ascites $(3.3 \%)$ and fluid collection (6.7\%). Almost all complications except two were classified as grade I according to the Clavien-Dindo grading system. ${ }^{27}$ There was one patient classified as grade III for requiring percutaneous drainage of pleural effusion. The other received blood transfusion, classified as grade II. Both of them underwent open surgical RFA. The higher complication rate of open RFA compared with laparoscopic RFA in this study was related to the combination of operations. Almost two-third of the patients $(75.8 \%)$ treated with open RFA underwent simultaneous liver resection or colectomy of extra malignant tumors. These complications, especially pleural effusion, are likely related to hepatic mobilization and liver resection. A study reported that combining resection of dominant liver tumors with RFA of the remaining lesions can be expected to increase the complication rate. Even if there was no statistical significance between the two groups when combined operation cases were excluded, the 
laparoscopic RFA group experienced lower incidence of complications $(62.5 \%$ vs $26.3 \%, p=0.102)$.

In the study of RFA for 231 unresectable hepatic tumors, the median length of hospital stay was 5 days after celiotomy. ${ }^{28}$ Also, in one of the other studies, after laparoscopic and open RFA, mean hospital stay was 1-3 days and 4-7 days, respectively. ${ }^{29}$ In our study, except in the case of simultaneous operation, mean hospital stay was 5.0 (3-14 days) and 11.5 days (7-27 days) after laparoscopic and open RFA, respectively $(p=0.02)$.

We think that the intraoperative approach enables accurate access to tumors when the location is superficial or close to adjacent organs. It also permits simultaneous liver or colon resection if necessary. The intraoperative approach allows for detection of additional hepatic or extrahepatic diseases through visualization. Of the two types of RFA approaches, laparoscopic RFA yielded better outcomes in terms of incomplete treatment, local recurrence, complication rates and length of hospital stay. The factors that contribute to positive results after laparoscopic RFA are as follows: because of the upward movement of the diaphragm by pneumoperitoneum, liver movement can be minimal; $12 \mathrm{mmHg}$ pneumoperitoneum causes a $40 \%$ decrease of portal vein flow, with a subsequent increase in RFA size; and the minimally invasive approach decreases the morbidity associated with a large incision. ${ }^{30}$ The laparoscopic approach is used most often for a limited number of tumors, particularly if mobilization of the liver or bowel is necessary, as well as for patients undergoing concomitant laparoscopic liver resection or colorectal resection.

In conclusion, laparoscopic RFA can be performed for malignant liver tumors with lower morbidity rates, less invasiveness and expense compared to an open surgical approach.

\section{REFERENCES}

1. Bruix J, Sherman M; American Association for the Study of Liver Diseases. Management of hepatocellular carcinoma: an update. Hepatology 2011;53:1020-1022.

2. Kudo $M$, Izumi $N$, Kokudo $N$, Matsui $O$, Sakamoto $M$, Nakashima O, et al; HCC Expert Panel of Japan Society of Hepatology. Management of hepatocellular carcinoma in Japan: Consensus-Based Clinical Practice Guidelines proposed by the Japan Society of Hepatology (JSH) 2010 updated version. Dig Dis 2011;29:339-364.

3. Minami Y, Kudo M. Radiofrequency ablation of hepatocellular carcinoma: current status. World J Radiol 2010;2:417-424.
4. Künzli BM, Abitabile P, Maurer CA. Radiofrequency ablation of liver tumors: actual limitations and potential solutions in the future. World J Hepatol 2011;3:8-14.

5. Minami Y, Kudo M. Radiofrequency ablation of hepatocellular carcinoma: a literature review. Int J Hepatol 2011;2011:104685.

6. Lee SD, Han HS, Cho JY, Yoon YS, Hwang DW, Jung K, et al. Safety and efficacy of laparoscopic radiofrequency ablation for hepatic malignancies. J Korean Surg Soc 2012;83:36-42.

7. Mulier S, Mulier P, Ni Y, Miao Y, Dupas B, Marchal G, et al. Complications of radiofrequency coagulation of liver tumours. Br J Surg 2002;89:1206-1222.

8. Curley SA, Marra P, Beaty K, Ellis LM, Vauthey JN, Abdalla EK, et al. Early and late complications after radiofrequency ablation of malignant liver tumors in 608 patients. Ann Surg 2004; 239:450-458.

9. Chhabra DG, Shah RC, Parikh V, Jagannath P. Radiofrequency ablation of liver tumors: experience with open and percutaneous approach. Indian J Gastroenterol 2006;25:66-70.

10. Bleicher RJ, Allegra DP, Nora DT, Wood TF, Foshag LJ, Bilchik AJ. Radiofrequency ablation in 447 complex unresectable liver tumors: lessons learned. Ann Surg Oncol 2003;10:52-58.

11. Santambrogio R, Bianchi P, Pasta A, Palmisano A, Montorsi M. Ultrasound-guided interventional procedures of the liver during laparoscopy: technical considerations. Surg Endosc 2002;16:349354.

12. Eisele RM, Zhukowa J, Chopra S, Schmidt SC, Neumann U, Pratschke J, et al. Results of liver resection in combination with radiofrequency ablation for hepatic malignancies. Eur J Surg Oncol 2010;36:269-274.

13. Kim HO, Kim SK, Son BH, Yoo CH, Hong HP, Cho YK, et al. Intraoperative radiofrequency ablation with or without tumorectomy for hepatocellular carcinoma in locations difficult for a percutaneous approach. Hepatobiliary Pancreat Dis Int 2009;8: 591-596.

14. Poon RT, Fan ST, Tsang FH, Wong J. Locoregional therapies for hepatocellular carcinoma: a critical review from the surgeon's perspective. Ann Surg 2002;235:466-486.

15. Santambrogio R, Podda M, Zuin M, Bertolini E, Bruno S, Cornalba GP, et al. Safety and efficacy of laparoscopic radiofrequency ablation of hepatocellular carcinoma in patients with liver cirrhosis. Surg Endosc 2003;17:1826-1832.

16. Okabayashi T, Kobayashi M, Akimori T, Akisawa N, Iwasaki $\mathrm{S}$, Onishi S, et al. Usefulness of laparoscopic radiofrequency ablation of hepatocellular carcinoma. Surg Technol Int 2005;14:177181.

17. Feng K, Yan J, Li X, Xia F, Ma K, Wang S, et al. A randomized controlled trial of radiofrequency ablation and surgical resection in the treatment of small hepatocellular carcinoma. J Hepatol 2012;57:794-802.

18. Ossip MG, Kachura JR, Ho CS. Radiofrequency ablation of liver tumors: local progression-free survival and factors for failure of effectiveness. J Vasc Interv Radiol 2004;15(suppl):208.

19. Mulier S, Ni Y, Jamart J, Ruers T, Marchal G, Michel L. Local recurrence after hepatic radiofrequency coagulation: multivariate meta-analysis and review of contributing factors. Ann Surg 2005;242:158-171.

20. Poon RT, Ng KK, Lam CM, Ai V, Yuen J, Fan ST, et al. Learning curve for radiofrequency ablation of liver tumors: prospective analysis of initial 100 patients in a tertiary institution. Ann Surg 2004;239:441-449.

21. Wong SL, Mangu PB, Choti MA, Crocenzi TS, Dodd GD 3rd, Dorfman GS, et al. American Society of Clinical Oncology 2009 clinical evidence review on radiofrequency ablation of hepatic metastases from colorectal cancer. J Clin Oncol 2010;28:493-508. 
22. Poon RT, Ng KK, Lam CM, Ai V, Yuen J, Fan ST. Effectiveness of radiofrequency ablation for hepatocellular carcinomas larger than $3 \mathrm{~cm}$ in diameter. Arch Surg 2004;139:281-287.

23. Ayav A, Germain A, Marchal F, Tierris I, Laurent V, Bazin C, et al. Radiofrequency ablation of unresectable liver tumors: factors associated with incomplete ablation or local recurrence. Am J Surg 2010;200:435-439.

24. Lam VW, Ng KK, Chok KS, Cheung TT, Yuen J, Tung H, et al. Incomplete ablation after radiofrequency ablation of hepatocellular carcinoma: analysis of risk factors and prognostic factors. Ann Surg Oncol 2008;15:782-790.

25. Siperstein AE, Berber E, Ballem N, Parikh RT. Survival after radiofrequency ablation of colorectal liver metastases: 10-year experience. Ann Surg 2007;246:559-565.

26. Siperstein A, Garland A, Engle K, Rogers S, Berber E, Foroutani $\mathrm{A}$, et al. Local recurrence after laparoscopic radiofrequency ther- mal ablation of hepatic tumors. Ann Surg Oncol 2000;7:106-113. 27. Dindo D, Demartines N, Clavien PA. Classification of surgical complications: a new proposal with evaluation in a cohort of 6336 patients and results of a survey. Ann Surg 2004;240:205-213.

28. Wood TF, Rose DM, Chung M, Allegra DP, Foshag LJ, Bilchik AJ. Radiofrequency ablation of 231 unresectable hepatic tumors: indications, limitations, and complications. Ann Surg Oncol 2000;7:593-600.

29. Vivarelli M, Guglielmi A, Ruzzenente A, Cucchetti A, Bellusci $\mathrm{R}$, Cordiano C, et al. Surgical resection versus percutaneous radiofrequency ablation in the treatment of hepatocellular carcinoma on cirrhotic liver. Ann Surg 2004;240:102-107.

30. Smith MK, Mutter D, Forbes LE, Mulier S, Marescaux J. The physiologic effect of the pneumoperitoneum on radiofrequency ablation. Surg Endosc 2004;18:35-38. 